J. Lake Sci.(湖泊科学), 2008, 20(6): 819-824

http://www.jlakes.org. E-mail: jlakes@niglas.ac.cn

(C)2008 by Journal of Lake Sciences

\title{
泥炭沼泽不同植物群落中地表糙度变化及其影响机制*
}

\author{
刘聚涛 ${ }^{1,2,3}$, 王升忠 ${ }^{3^{* *}}$, 高俊峰 ${ }^{1}$, 姜加虎 ${ }^{1}$ \\ (1: 中国科学院南京地理与湖泊研究所, 南京 210008) \\ (2: 中国科学院研究生院, 北京 100049) \\ (3: 东北师范大学国家环境保护湿地生态与植被恢复重点实验室，长春 130024)
}

摘 要: 地表䊅度是衡量地表径流形成的一个重要指标. 以东北区典型泥炭沼泽一一金川泥炭沼泽为例, 考虑地表坡度影响, 用链条法对不同群落中糙度系数指标进行计算, 并以泥炭沼泽中物种多样性、踏头个数以及踏头形态差异变率系数为主, 初 步分析泥炭泥泽地表粘度的变化机制, 结果表明: 在芦苇-影囊苔草群落、臌囊苔草群落和油桦-臌囊苔草-泥炭藓群落三个植 物群落中, 粘度系数指标的变化与群落中物种丰富度和生物多样性变化相一致; 糙度系数变化与踏头个数呈负相关关系, 与 踏头形态差异变率系数呈正相关关系. 说明物种多样性越小, 生态优势度越大, 优势种植物越少, 踏头个数越多, 踏头形态变 率系数越小, 微地貌形态发育相对较一致, 䊁度系数越小; 反之, 则地表䊅度系数越大.

关键词: 泥炭沼泽; 糙度系数指标; 物种多样性; 踏头个数; 踏头形态差异

\section{Changeness of the surface roughness distribution of different plant communities and its biological mechanism}

\author{
LIU Jutao ${ }^{1,2,3}$, WANG Shengzhong ${ }^{3}$, GAO Junfeng ${ }^{1} \&$ JIANG Jiahu ${ }^{1}$ \\ (1: Nanjing Institute of Geography and Limnology, Chinese Academy of Sciences, Nanjing 210008, P.R.China) \\ (2: Graduate School of Chinese Academy of Sciences, Beijing 100049, P.R.China) \\ (3: State Environmental Protection Key Laboratory of Wetland Ecology and Vegetation Restoration, Northeast Normal University, \\ Changchun 130024, P.R.China)
}

Abstract: Surface roughness was an important indicator for the formation of surface runoff. This paper takes peat mire of Northeast Jinchuan peat mire as an example, considering impacts of surface slope to measure the roughness index with the chain method in different plant communities. Based on the plant richness, the number of hummock and the coefficient of variation of the hummock forms, we analyzed the mechanism of the changes of surface roughness. The results showed: in three Phragmites australis-Carex schmidtii community, Carex schmidtii community and Betula ovilifolia-Carex schmidtii-Sphagnum palustre community, roughness coefficients changed consistently with changes of species richness and biodiversity of the communities. The changes of the roughness were negatively correlated with number of the hummocks, and positively correlated with coefficient of variation of the hummock forms. It showed that, the smaller the species richness, the larger the ecological dominance; the fewer the dominant plant, the more the number of the hummocks; and the smaller the coefficient of variation of the hummock forms, the more consistence the forming of the micro-geomorphologic relief and the smaller the roughness coefficient. Otherwise, the roughness coefficient became bigger.

Keywords: Peat mire; roughness coefficient index; palnt community; biological mechanism; hummock form

地表䊅度系数是指示地表径流形成的一个重要指标, 它对地表径流流速、流态、渗透及其冲刷能力

* 吉林省科技发展计划重大项目(2004040405-4)和科技部科技基础性工作专项 (2006FY110600) 联合资助. 2007-11-04 收稿; 2008-05-20 收修改稿. 刘聚涛, 男, 1983 年生, 博士研究生; E-mail: liujutao126@163.com.

** 通讯作者; E-mail: wangsz362@nenu.edu.cn. 
的影响作用很大 ${ }^{[1]}$, 在水土保持中和土壤侵蚀研究中是一个重要的因子 ${ }^{[2]}$. 影响地表粘度系数的因素与 地形坡度、植被盖度、以及枯落物组成、数量、厚度有关, 腐烂得枯枝落叶可增加地表有机质含量, 提 高土壤生物和微生物种类和数量 ${ }^{[1,3]}$. 关于地表糙度影响因素的研究多集中于坡耕地中, Romkens 等 ${ }^{[4-5]}$ 认 为随着复耕次数的增加, 地表粘度减小; Allmaras 等 ${ }^{[4,6]}$ 、 Lyles 等 ${ }^{[4,7]}$ 研究表明土壤性质对地表粘度也产生 影响; 降雨对地表粘度也产生重要的影响 ${ }^{[4,8-9]}$. 而在泥炭地中, 植被盖度较大, 地形坡度较小, 通常认为 地表粘度较大 ${ }^{\mathbb{1} 2}$ ，仅仅局限于定性描述，并没有对其进行定量计算，也没有对泥炭沼泽中地表粘度的影 响机制进行分析.

泥炭沼泽是指具有现代泥炭积累过程的泥炭地, 其中有机质积累大于有机质的分解. 本文以剑泥炭 沼泽为研究对象, 针对不同植物群落进行地表粘度的定量计算, 并初步分析其在不同植物群落中变化的 影响机制, 为进一步研究泥炭沼泽中地表径流形成机制、泥炭沼泽水文功能机制打下基础.

\section{1 研究区概况}

金川泥炭沼泽(图 1)位于吉林省辉南县金川镇西 $1 \mathrm{~km}$ 左右, 地理坐标为 $42^{\circ} 20^{\prime} 56^{\prime \prime} \mathrm{N}, 126^{\circ} 22^{\prime} 51^{\prime \prime} \mathrm{E}$. 金川

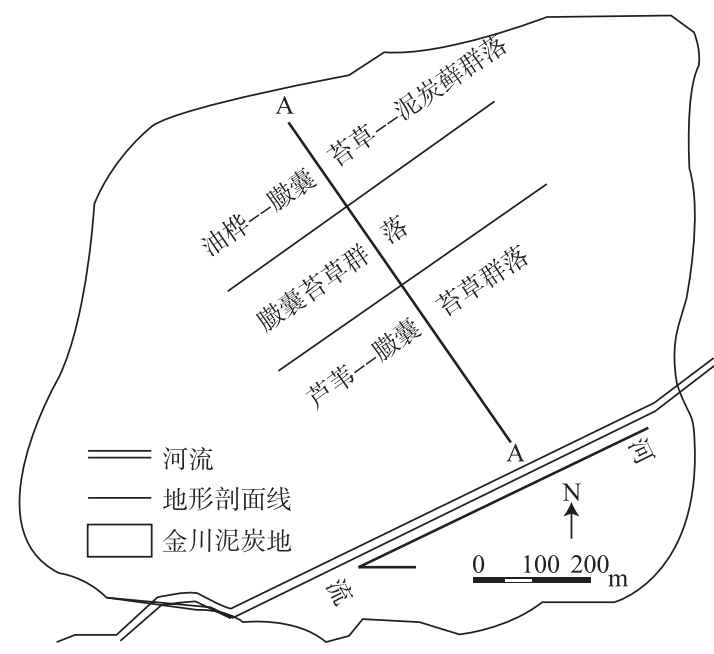

图 1 金川泥炭沼泽样带示意图 Fig.1 Sketch of simple line of Jinchuan 泥炭沼泽发育在第四纪火山口内，泥炭厚度一般 3-6m, 地表海拔 613-616m, 东西长 $1440 \mathrm{~m}$, 南北 近 $1160 \mathrm{~m}$, 面积约为 $1.1 \mathrm{~km}^{2}$. 气候冷湿, 年平均气 温 $3.3^{\circ} \mathrm{C}$ 左右, 年均降水量 $1053.9 \mathrm{~mm}$, 且多集中 于 7、8 月份, 此时泥炭沼泽内季节性积水达 $10 \mathrm{~cm}$ 左右. 从河流到山前分布着芦苇一臌囊苔草、臌囊 苔草以及油桦一腤囊苔草－泥炭藓三种植物群落.

\section{2 研究方法}

选取从河流到山前方向带状区域, 采用典型 剖面 AA 计算泥炭地剖面的坡度; 并在芦苇一臌 囊苔草、臌囊苔草以及油桦一䐻囊苔草－泥炭藓 三种植物群落中分别设置 5 个样点进行地表粘度 定量计算, 3 个样方进行物种多样性分析, 4 个 $1 \mathrm{~m}$ $\times 1 \mathrm{~m}$ 样方进行踏头形态差异分析. 根据植物群 落物种多样性和踏头微地貌形态分析该泥炭沼泽 中不同植物群落的地表粘度变化及其变化机制.

\section{1 泥炭沼泽样带坡度测量}

选取垂直河流流向长度为 $700 \mathrm{~m}$ 的样带, 应用连通器原理采用 $25 \mathrm{~m}$ 间隔来测量两点之间的相对高程, 从而进行坡度计算.

\section{2 地表粘度计算}

国内多运用链条法进行徙度系数的计算, 吴发启等 ${ }^{[2]}$ 用链条法与小干尺法作比较，证明了链条法测 得的数据离散程度小, 较对称, 稳定性高, 并且链条法测量的效率高, 且容易消除人为因素影响. 链条法 选用链条长度 $L_{1}=100 \mathrm{~cm}$, 测量时沿径流方向贴地面放置, 其顺坡长度 $L_{2}$ 随地形起伏增大而减小, 计算 出链条长度的减小值 $L_{1}-L_{2}$, 即可计算出糙度指标 $C^{[10-11]}$.

式中, $C$ 值越大, 表示䅚度系数越大.

$$
C=\left[\left(L_{1}-L_{2}\right) / L_{1}\right] \times 100
$$

$$
C^{\prime}=\left(C_{1}+C_{2}+\ldots \ldots+C_{j}\right) / i
$$

式中: $C_{i}$ 表示第 $i$ 个样方的粘度系数指标; $i$ 表示总共的样方个数, 本文中 $i=5$.

(1) 马学慧, 张则有, 赵楚年. 若尔盖沼泽的水热特征. 长春: 东北师范大学地理系泥炭沼泽研究室, 1963: 16 .

(2) 张则有. 试论沼泽水源补给类型和水分运动. 长春: 东北师范大学地理系泥炭沼泽研究室, 1984: 23. 


\section{3 踏头样方调查}

在金川泥炭沼泽中，踏头的平面形态近似椭圆和圆状，长轴和短轴是指示椭圆的重要的形态指标， 根据植物群落空间分布，在三种植物群落中分别选取 4 个 $1 \mathrm{~m} \times 1 \mathrm{~m}$ 样方，调查该样方内的踏头个数及其该 踏头的长轴和短轴, 应用长轴与短轴之差作为踏头形态差异的指示参数, 采用 SPSS12.0 进行均值分析和 单向方差检验分析.

\section{4 植物群落物种多样性分析}

在芦苇-臌囊苔草群落、臌囊苔草群落和油华-臌囊苔草-泥炭藓群落3个植物群落(分别用群落A、群 落B和群落 $\mathrm{C}$ 表示) 中设置样方, 灌木植物样方为 $2 \mathrm{~m} \times 2 \mathrm{~m}$, 草本植物样方为 $1 \mathrm{~m} \times 1 \mathrm{~m}$, 采用重要值、物种丰富 度、物种多样性指数和生态优势度指数进行物种多样性分析.

重要值为相对盖度、相对多度和相对频度三者之和; 物种丰富度指数为每个样地内的物种数. 物种 多样性指数 $H$ 采用Shannon-Wiener ${ }^{[12]}$ 指数计算; 生态优势度 $C$ 选用Simpsonl ${ }^{[13-14]}$ 生态优势度指标计算.

\section{3 结果与分析}

\section{1 泥炭沼泽地形特征}

以剖面上距离河流最近的样点为基准点, 测量计 算金川泥炭沼泽样带剖面相对高度示意图(图2), 根据 该图可以看出, 泥炭沼泽整体上是从山前向河流方向 倾斜地表高程随着距河流的距离增加而增加. 剖面的 总体坡度约为 $0.001, S_{\text {max }}=0.00364$. 则在该泥炭沼泽中, 地表径流方向为从山前流向河流的垂直河流方向, 由 于坡度较小, 对地表径流的形成产生的影响较小.

\section{2 植物群落多样性分析}

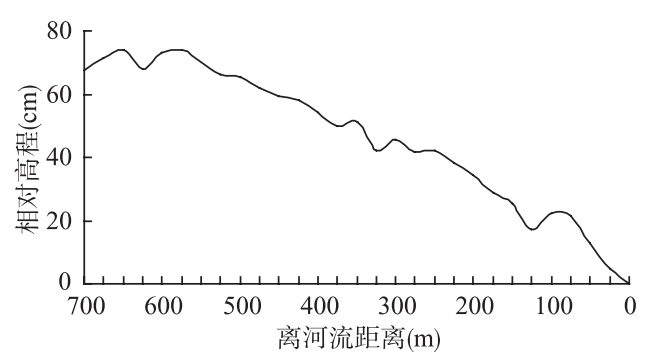

图 2 泥炭沼泽样带地形剖面示意图

Fig.2 Sketch of the transect of the peat mire

根据植物样方调查, 植物群落多样性特征如下表. 在群落 A、群落 B 和群落 C 中, 优势种植物数分别 为 $2 、 1$ 和 3 , 物种的丰富度分别为 $9 、 8$ 和 13 , 物种多样性为 $1.124313 、 1.085642$ 和 2.148366 ; 物种丰富 度指数河物种多样性指数变化趋势具有一致性, 先减小后增大; 而生态优势度先增大后减小, 说明物种 丰富度越大, 生物多样性越大, 生态优势度则相应减小; 而且优势种植物越单一, 物种丰富度越小, 则该 区的生态优势度相对较大.

表 1 植物群落多样性特征

Tab.1 The quantitative characteristics of plant community

\begin{tabular}{|c|c|c|c|c|}
\hline 群落 & 优势种植物 & 物种丰富度 $(R)$ & 物种多样性指数 $(H)$ & 生态优势度 $(C)$ \\
\hline 芦苇-臌囊苔草群落(A) & $\begin{array}{l}\text { 臌囊苔草(Carex schmidtii) } \\
\text { 芦苇(Phragmites australis) }\end{array}$ & 9 & 1.124313 & 0.445163 \\
\hline $\begin{array}{l}\text { 臌囊苔草群落(B) } \\
\text { 油桦-臌囊苔草-泥炭藓 }\end{array}$ & $\begin{array}{l}\text { 臌囊苔草(Carex schmidtii) } \\
\text { 油桦(Betula ovilifolia) }\end{array}$ & 8 & 1.085642 & 0.528138 \\
\hline 群落(C) & $\begin{array}{l}\text { 臌囊苔草(Carex schmidtii) } \\
\text { 泥炭藓(Sphagnum) }\end{array}$ & 13 & 2.148366 & 0.1635963 \\
\hline
\end{tabular}

\section{3 不同植物群落踏头形态分析}

通过 SPSS 对不同群落间踏头形态差异分析(表 2), 可以看出在群落 A、群落 B 和群落 C 种植物群落 间, 踏头形态差异指标的 $P=0.001<0.005$, 则在这 3 个各群落中踏头形态存在显著差异.

群落 $\mathrm{A}$ 、群落 $\mathrm{B}$ 和群落 $\mathrm{C}$ 中踏头的数量分别为 $16 、 24$ 和 13 ; 踏头的形态参数长宽差值的波动范围 和标准差分别为 $35,8.663 ; 3,1.013 ; 40,13.213$; 踏头形态的变率系数分别为 $0.855,0.426,1.023$ (表 3). 在 这 3 种植物群落中, 踏头的数量变化先增加后减小, 而踏头形态参数的波动范围和变率系数的变化具有 
一致性, 先减小后增加. 在群落 C、群落 A 和群落 B3 种植物群落中, 变率系数与踏头个数的相关关系 $R^{2}=0.9999$, 说明变率系数与踏头个数呈明显负相关关系(图 3).

表 2 不同群落间踏头形态差异分析

Tab.2 Analysis of form difference of different communities

\begin{tabular}{cccccc}
\hline 群落 & 离均差平方和 & 自由度 & 均方差 & 自由度 & $P$ 值 \\
\hline 群落间 & 1120.872 & 2 & 560.436 & 8.637 & 0.001 \\
群落内部 & 3244.298 & 50 & 64.886 & & \\
群落总数 & 4365.170 & 52 & & & \\
\hline
\end{tabular}

表 3 不同群落踏头形态参数分析

Tab.3 Analysis of form parameter of different communities

\begin{tabular}{ccccccc}
\hline 群落 & 平均值 & 数量 & 差值范围 & 标准差 & 平均标准差 & 变率系数 \\
\hline 芦苇-臌囊苔草群落(A) & 10.13 & 16 & 35 & 8.663 & 2.166 & 0.855 \\
臌囊苔草群落(B) & 2.38 & 24 & 3 & 1.013 & 0.207 & 0.426 \\
油桦-臌囊苔草-泥炭藓群落(C) & 12.92 & 13 & 40 & 13.213 & 3.665 & 1.023 \\
总和 & 7.30 & 53 & 40 & 9.162 & 1.259 & 1.255 \\
\hline
\end{tabular}
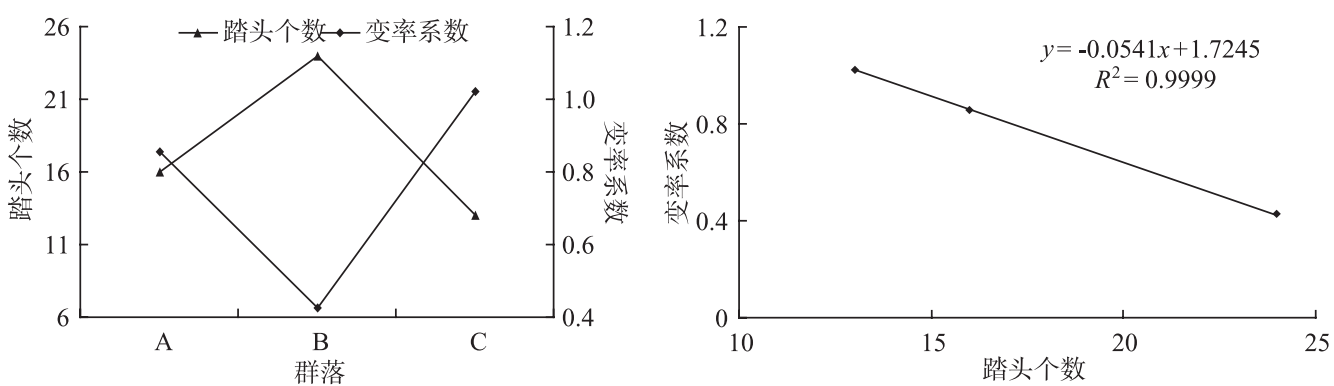

图 3 群落 $\mathrm{A}$ 、群落 $\mathrm{B}$ 和群落 $\mathrm{C}$ 中踏头个数与形态差异变率系数变化趋势及其相关关系

Fig. 3 The changeness of number of the hummock and the coefficient of variation and its correlation

变率系数的大小决定了形态变化的幅度大小, 变率系数越小, 形态发育越一致, 变率系数越大, 形 态差异越大. 根据图 3, 在群落 B 中, 踏头形态变率系数最小, 在群落 C 中踏头形态变率系数最大. 而且, 在群落 $\mathrm{A}$ 、群落 $\mathrm{B}$ 和群落 $\mathrm{C}$ 中, 优势种植物个数分别为 $2 、 1 、 3$, 生态优势度分别为 $0.445163 、 0.528138$ 和 0.1635963 , 说明优势种植物越单一, 生态优势度越大, 而且在该群落中踏头数量越多, 踏头形态的变 率系数越小, 则踏头形态发育越一致; 优势种植物越多, 生态优势度越小, 而且踏头的数量越少，踏头的 形态变化较大，则踏头形态发育差异较大(表 3).

\section{4 地表粮度变化的生物影响机制分析}

3.4.1 不同植物群落中地表糙度系数变化 根据式(1)和式(2)计算可得: 群落 $\mathrm{A}$ 、群落 $\mathrm{B}$ 和群落 $\mathrm{C} 3$ 种植物 群落中地表䊁度系数分别为 $29 、 12$ 和 32.6 ; 说明沿着地表高度的相对增加, 地表鋉度系数先减小后增加, 在臌囊苔草群落中最小(图 4),

3.4.2 物种多样性对地表粘度变化的影响分析 在群落 $\mathrm{A} 、 \mathrm{~B}$ 和 C 中, 物种丰富度指数分别为 $9 、 8 、 13$, 物 种多样性指数分别为 $1.124313 、 1.085642$ 和 2.148366 (表 1), 粘度系数指标本别为 $29 、 12$ 和 32.6 , 三者具 有相同的变化趋势. 粘度系数指标与物种丰富度指数的相关系数 $R^{2}=0.5912$, 呈现一定的正相关关系. 

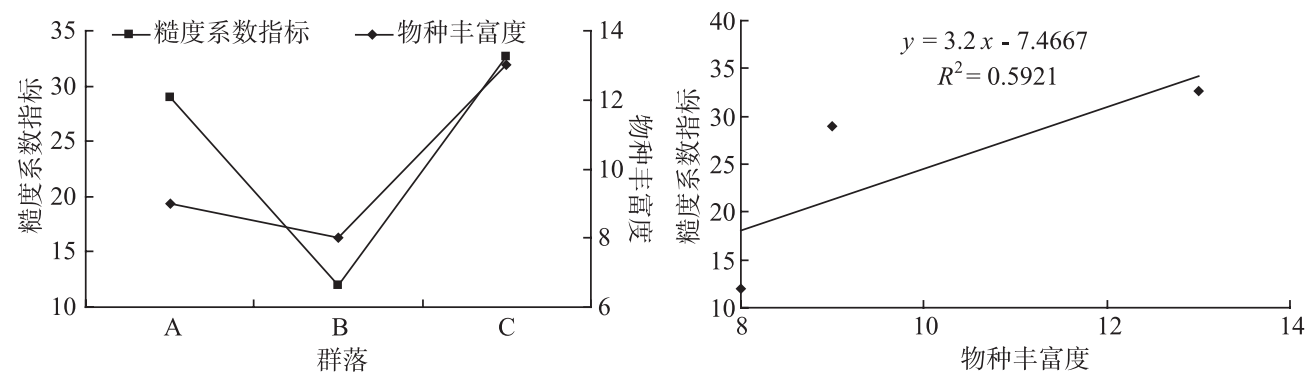

图 4 群落 $\mathrm{A}$ 、群落 $\mathrm{B}$ 和群落 $\mathrm{C}$ 中䊁度系数指标与物种丰富度指数变化趋势及其相关关系

Fig.4 The changeness of the roughness index and the species richness and its correlation

3.4.3 不同群落踏头个数对地表䊁度变化的影响分析 在群落 $\mathrm{A}$ 、群落 $\mathrm{B}$ 和群落 $\mathrm{C}$ 中, 踏头个数分别为 16 、 24 和 13 , 粘度系数指标本别为 $29 、 12$ 和 32.6 , 踏头个数和粘度系数变化趋势相反, 䊁度系数指标与踏头 个数相关系数 $R^{2}=0.9895$, 说明两者呈现较强的负相关关系(图 5), 糙度系数指标随着踏头个数的增加线 性减少。
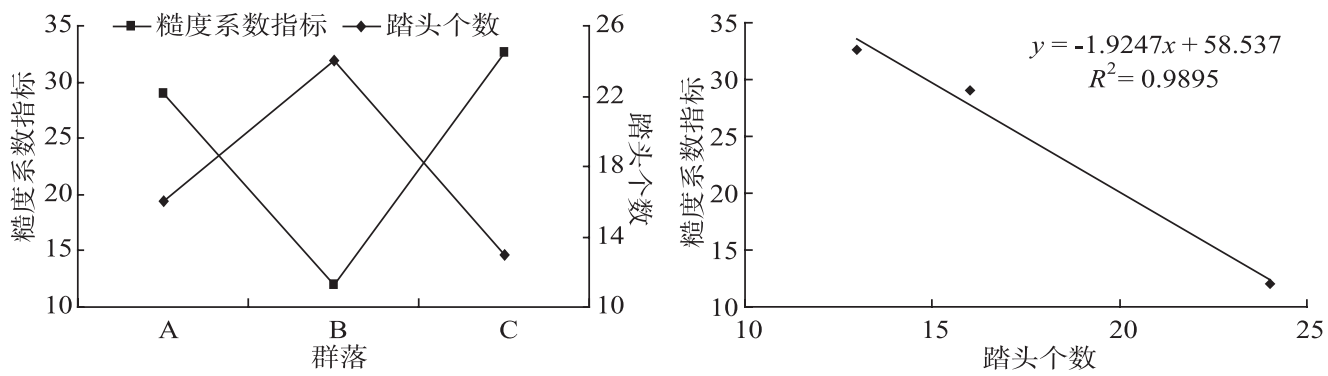

图 5 群落 $\mathrm{A}$ 、群落 $\mathrm{B}$ 和群落 $\mathrm{C}$ 中䊅度系数指标与踏头个数变化趋势及其相关关系

Fig.5 The changeness of the roughness index and the number of the hummock in the three plant communities and its correlation

3.4.4 不同群落踏头形态差异对地表粘度变化的影响分析 在群落 $\mathrm{A}$ 、群落 $\mathrm{B}$ 和群落 $\mathrm{C}$ 中, 踏头形态差异 变率系数分别为 $0.855 、 0.426 、 1.023$; 粘度系数指标本别为 $29 、 12$ 和 32.6 . 踏头形态差异变率系数与粘 度系数指标变化呈现相同的变化趋势, 两者之间相关系数 $R^{2}=0.9875$, 呈现较强的正相关关系, 䊁度系数 指标随着变率系数的增加而增大(图 6).
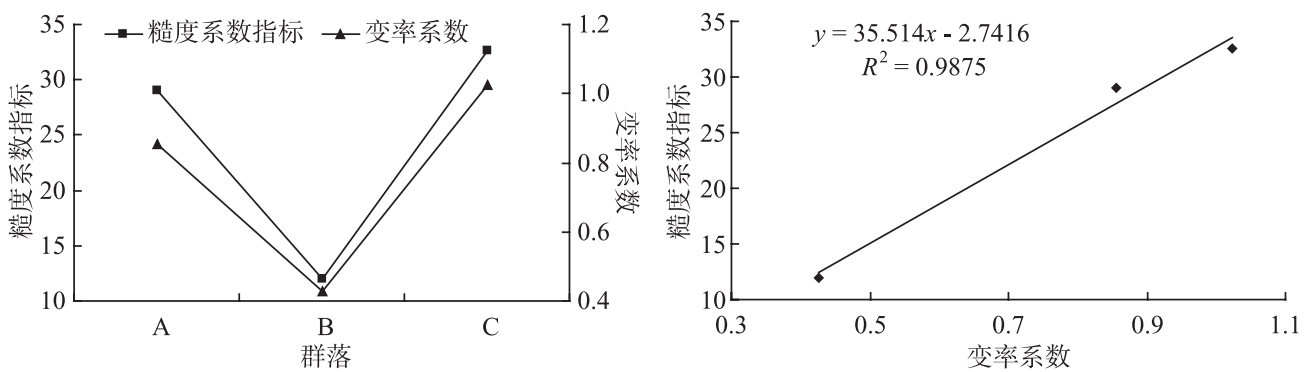

图 6 群落 $\mathrm{A}$ 、群落 $\mathrm{B}$ 和群落 $\mathrm{C}$ 中䊁度系数指标与形态差异变率系数变化趋势及其相关关系

Fig.6 The changeness of the roughness index and the coefficient of variation and its correlation 


\section{4 结论与讨论}

（1）随着地表高程的相对增加，群落 $\mathrm{A}$ 、群落 $\mathrm{B}$ 和群落 $\mathrm{C}$ 在空间上连续分布. 在这 3 个植物群落中, 物 种丰富度先减小后增加, 生物多样性呈现相同的规律; 生态优势度则随着物种多样性的增加而减小, 优 势种植物越单一, 生态优势度越大. 踏头个数先增加后减小, 踏头形态变率系数和䊅度系数指标则先减 小后增加.

(2) 地表䊅度系数变化受物种多样性、踏头个数和踏头形态差异的变率系数的影响. 地表䊅度系数指 标与物种丰富度指数、物种多样性呈现一定的正相关关系, 具有一定的相关性; 与踏头个数和踏头形态 差异变率系数呈较强负相关和正相关关系.

（3）在泥炭沼泽中, 踏头形态分异是微地貌形态分异的重要指示. 地表粘度系数在金川泥炭沼泽中 沿群落 A、群落 B 和群落 C 空间分布先减小后增加. 在群落 B 中, 物种多样性最小, 生态优势度最大, 踏 头个数最多, 踏头形态差异变率系数最小, 地表䊁度系数也最小. 这可能是由于该群落中物种多样性越 小，优势种植物越单一，该植物形成的踏头个数越多，从而踏头形态发育较一致，从而减小了地表䊅度 系数. 而物种多样性越大, 而且优势种植物越多, 样方内踏头个数越少, 踏头形态差异变率系数越大, 踏 头发育形态差异较大，该区域异质性增强，从而使粘度系数增加.

(4) 在野外调查试验过程中, 采取的试验方法具有简便、可行性, 在各个群落中的调查结果具有可比 性，进行统计分析，可信度较高.

(5) 地表粘度系数是影响地表径流形成的重要因素. 在泥炭沼泽中研究地表䊁度的影响机制, 对泥 炭沼泽的地表径流形成及其方向、营养物质迁移以及蓄水功能机制、调节径流起着重要的作用. 在金川 泥炭沼泽中，地形剖面上坡度最大值为 0.00364 , 坡度较小，本文从生物方面对泥炭沼泽的糙度系数变化 影响因素进行了初步分析, 这为泥炭沼泽中深人研究地表径流形成机制打下了基础.

(6) 在今后的研究中, 还要考虑在物种多样性和粘度系数以及踏头形态差异调查时, 样方数量以及 大小的设置对地表粘度变化的影响, 从而对地表䊁度在泥炭沼泽中的影响机制进行深人研究.

\section{5 参考文献}

[1] 阳海龙, 朱金兆, 齐 实等. 三峡库区森林流域林地的地表粘率系数. 北京林业大学学报, 2005, 27(1): 38-41.

[2] 吴发启, 赵晓光, 刘秉正等. 地表粘度的量测方法及对坡面径流和侵蚀的影响. 西北林学院学报, 1998, 13(2): 15-19.

[3] 张增哲, 余新晓. 中国森林水文研究现状和主要成果综述. 见: 潘维俦编. 全国森林水文学术讨论会文集. 北京: 测绘出 版社, 1989: 918-925.

[4] 吴发启, 郑子成, 何淑勤. 坡耕地地表䊅度的研究进展. 西北林学院学报, 2002, 17(3): 38-43.

[5] Romkens MJM, Wang JY. Effect of tillage on surface roughness. Trans ASAE, 1986, 29: 429-433.

[6] Allmaras RR, Burwell RE, Holt RF. Plow-layer porosity and surface roughness tillage as affected by initial porosity and soil moisture at tillage time. Soil Sci Soc Am Am Proc, 1967, 31: 550-556.

[7] Lyles L, Woodruff NP. Surface soil cloddiness in relation to soil density at time of tillage. Soil Sci, 1961, 91: 178-182.

[8] Romkens MJM, Wang JY. The effect of tillage on surface roughness. Am Soc Agric Eng, 1984, 84: 2026-2042.

[9] Romkens MJM, Wang JY. Soil roughness of tillage system from rainfall. Am Soc Agric Eng, 1985, 85: 2048-2068.

[10] 吴发启, 郑子成. 坡耕地地表䊁度的量测与计算. 水土保持通报, 2005, 25(5): 71-74.

[11] Ali Saleh. Soil roughness measurement; chain method. J Soil and Water Cons, 1993, 48(6): 527-529.

[12] 马克平. 生物群落多样性的测度方法. 见: 钱迎倩, 马克平编. 生物多样性研究的原理与方法. 北京: 中国科学技术出版 社, 1994: 141-165.

[13] 徐广平, 张德罡 蒲小鹏等. 东祁连山高寒草地植物群落二维极点排序. 草原与草坪, 2005, 3: 42-45.

[14] 马克平, 黄建辉, 于顺利等. 北京东灵山地区植物群落多样性的研究 (II): 丰富度、均匀度和物种多样性指数. 生态学报, 1995, 15(3): 268-277. 